\title{
Effect of ketoconazole on the pharmacokinetics of axitinib in healthy volunteers
}

\author{
Yazdi K. Pithavala • Warren Tong • Janessa Mount • Sadayappan V. Rahavendran • \\ May Garrett • Brian Hee • Paulina Selaru • Nenad Sarapa • Karen J. Klamerus
}

Received: 24 March 2010 / Accepted: 26 July 2010 /Published online: 26 August 2010

(C) The Author(s) 2010. This article is published with open access at Springerlink.com

\begin{abstract}
Summary Objective Axitinib (AG-013736), an oral, potent, and selective inhibitor of vascular endothelial growth factor receptors 1,2 , and 3 , is metabolized primarily by cytochrome $\mathrm{P} 450$ (CYP) $3 \mathrm{~A}$ with minor contributions from CYP1A2, CYP2C19, and glucuronidation. Co-administration with CYP inhibitors may increase systemic exposure to axitinib and alter its safety profile. This study evaluated changes in axitinib plasma pharmacokinetic parameters and assessed safety and tolerability in healthy subjects, following axitinib co-administration with the potent CYP3A inhibitor ketoconazole. Methods In this randomized, single-blind, twoway crossover study, 32 healthy volunteers received placebo, followed by a single 5-mg oral dose of axitinib, administered either alone or on the fourth day of dosing with oral ketoconazole (400 mg/day for 7 days). Results Axitinib exposure was significantly increased in the presence of ketoconazole, with a geometric mean ratio for area under the plasma concentration-time curve from time zero to infinity
\end{abstract}

\footnotetext{
Pfizer Oncology,

10555 Science Center Drive,

San Diego, CA 92121, USA

e-mail: yazdi.pithavala@pfizer.com

Present Address:

W. Tong

Allergan Inc.,

2525 Dupont Drive,

Irvine, CA 92612, USA

Present Address:

N. Sarapa

Hoffmann-La Roche Inc.,

340 Kingsland Street,

Nutley, NJ 07110, USA
}

Funding This study was sponsored by Pfizer Inc.

Y. K. Pithavala $(\bowtie) \cdot$ W. Tong $\cdot$ J. Mount $\cdot$ S. V. Rahavendran

M. Garrett $\cdot$ B. Hee $\cdot$ P. Selaru $\cdot$ N. Sarapa $\cdot$ K. J. Klamerus of 2.06 (90\% confidence interval [CI]: 1.84-2.30) and a geometric mean ratio for maximum plasma concentration $\left(\mathrm{C}_{\max }\right)$ of 1.50 (90\% CI: 1.33-1.70). For axitinib alone or with ketoconazole, $\mathrm{C}_{\max }$ occurred 1.5 and $2.0 \mathrm{~h}$ after dosing, respectively. Adverse events were predominantly mild; the most commonly reported treatment-related adverse events were headache and nausea. Conclusions Axitinib plasma exposures and peak concentrations were increased following concurrent administration of axitinib and ketoconazole in healthy volunteers. Axitinib alone and in combination with ketoconazole was well tolerated. These findings provide an upper exposure for expected axitinib plasma concentrations in the presence of potent metabolic inhibition.

Keywords Axitinib - Ketoconazole Pharmacokinetics . CYP3A · TaqMan ${ }^{\circledR}$ allelic discrimination · Simcyp ${ }^{\circledR}$. Corrected QT. Drug interaction

\section{Introduction}

Axitinib (AG-013736) is an oral, potent, and selective inhibitor of vascular endothelial growth factor receptors 1,2 , and 3 that induces tumor regression [1]. Pre-clinical tumor growth inhibition studies identified an effective axitinib concentration of $0.28-0.85 \mathrm{nmol} / \mathrm{L}$ [1]. Axitinib plasma concentrations observed in clinical trials after dosing $(5 \mathrm{mg}$ twice daily [BID]) averaged $0.19 \pm 0.12 \mathrm{nmol} / \mathrm{L}$ [1]. Phase II trials evaluating this dose in approximately 300 patients have demonstrated antitumor activity combined with acceptable tolerability across multiple tumor types, including metastatic renal cell cancer, non-small cell lung cancer, melanoma, and thyroid cancer [2-6]. The pharmacokinetics of axitinib are generally linear [7]. Oral absorption occurs rapidly, with 
peak plasma concentrations observed $1-4 \mathrm{~h}$ after dosing in the fed state. Axitinib has an effective plasma terminal halflife of $2-5 \mathrm{~h}$ and an oral absolute bioavailability of approximately $58 \%[7,8]$.

In vitro studies with recombinant cytochrome $\mathrm{P} 450$ (CYP) enzymes and human liver microsomes showed that axitinib is primarily metabolized by oxidation via the CYP3A isoenzyme and to a lesser extent by CYP1A2, CYP2C19, and uridine diphosphate glucuronsyltransferase (UGT) 1A1 [8]. The major circulating metabolites in human plasma are an $\mathrm{N}$-glucuronide product and a sulfoxide; the putative metabolic pathways for axitinib have been determined [9], and a schematic is provided in Fig. 1. In a human liver microsomal preparation, ketoconazole, a potent CYP3A inhibitor, blocked axitinib metabolism with a $50 \%$ inhibitory concentration $\left(\mathrm{IC}_{50}\right)$ of $0.4 \mu \mathrm{M}$. In vitro, ketoconazole has also been reported to inhibit UGT2B7-mediated glucuronidation of zidovudine and morphine and UGT1A1-mediated glucuronidation of $\mathrm{SN}-38$, the irinotecan metabolite [10]. These findings suggest a mechanistic basis by which drugs that affect the activity of CYP3A and UGT1A1 isozymes could alter the pharmacokinetics of axitinib. This is further supported by the observation of reduced axitinib exposure in a patient who was also treated with phenytoin, a potent inducer of multiple CYP enzymes, during the first-in-human (FIH) phase I study of axitinib in patients with advanced solid tumors [7]. Concurrent administration of phenytoin reduced the area under the plasma concentration-time curve (AUC) from time zero to $24 \mathrm{~h}\left(\mathrm{AUC}_{0-24}\right)$ and maximum plasma concentration $\left(\mathrm{C}_{\max }\right)$ of axitinib approximately 10 -fold. Study protocols currently prohibit use of drugs known to be potent inducers of the CYP3A and CYP1A2 isozymes during axitinib treatment.

Co-administration of a CYP3A inhibitor such as ketoconazole could have the opposite effect and lead to elevated plasma exposure to axitinib, potentially increasing the frequency and severity of adverse events. This randomized, single-blind, two-way crossover study evaluated the effects of repeated doses of ketoconazole plus a single axitinib dose on axitinib pharmacokinetic parameters in healthy volunteers. A separate study evaluated the effects of a potent CYP3A inducer on axitinib plasma exposure in healthy volunteers [8].

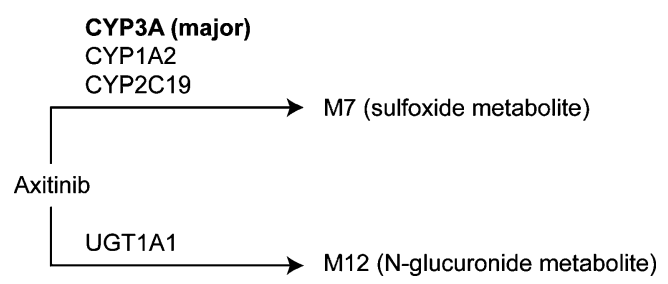

Fig. 1 Schematic of axitinib metabolism in humans

\section{Methods}

Subjects

Adults aged 18-55 years who were assessed as healthy based on a detailed medical examination, which included medical history, blood pressure (BP) and pulse-rate measurements, a 12-lead electrocardiogram (ECG) test, and clinical laboratory evaluations, were eligible to participate in the study. Subjects had a body mass index of 18$30 \mathrm{~kg} / \mathrm{m}^{2}$, a total body weight $>50 \mathrm{~kg}$, and normal ECG and resting BP measurement $(<140 / 90 \mathrm{~mm} \mathrm{Hg})$. Volunteers agreed to abstain from strenuous physical activity and consumption of products containing grapefruit, caffeine, xanthine, or alcohol from 2-4 days prior to initiating the study until collection of the final pharmacokinetic samples. Exclusion criteria were conditions that might influence the absorption, distribution, metabolism, or excretion of axitinib or ketoconazole: recent history of drug abuse, high levels of alcohol consumption, or use of products containing tobacco or nicotine; donation of $>500 \mathrm{ml}$ of blood within 56 days before beginning study treatment; use of prescription or non-prescription drugs or supplements (other than acetaminophen) within 14 days before initiating treatment (28 days for herbal supplements and hormonal contraception methods or 6 months for depot medroxyprogesterone acetate); or treatment with an investigational agent or use of any known CYP450 enzyme-inducing or -inhibiting drug within 30 days of beginning study medication.

\section{Study design}

This was a randomized, two-way crossover study conducted in healthy volunteers. The primary objective was to characterize changes in axitinib plasma pharmacokinetic parameters when a single dose of axitinib was co-administered with repeated doses of ketoconazole to healthy subjects. Secondary objectives included assessing the safety and tolerability of axitinib administered with ketoconazole, as well as evaluating the effects of a single axitinib dose on the corrected QT (QTc) interval and BP when administered alone or in combination with ketoconazole.

This study was approved by the institutional review board or ethics committee of each participating center and was carried out in accordance with the ethical principles originating in or derived from the Declaration of Helsinki. Additionally, this trial complied with informed consent regulations and the International Conference on Harmonization Good Clinical Practice guidelines, as well as applicable local laws and regulatory requirements. Written informed consent was obtained prior to subjects entering the study. 


\section{Treatment}

Placebo treatment was administered to all subjects on day -1 to characterize QT under the condition of no therapy. Using a computer-generated randomization schedule, subjects were assigned to receive either axitinib alone (treatment A) or combination treatment with ketoconazole plus axitinib (treatment B). Treatments were administered to subjects in one of two different sequences $(\mathrm{A} \rightarrow \mathrm{B}$ or $\mathrm{B} \rightarrow \mathrm{A})$ separated by a 14day wash-out period (Fig. 2). During treatment A, volunteers received a single, oral, 5-mg dose of axitinib on day 1 . During treatment $\mathrm{B}$, volunteers received oral doses of ketoconazole $400 \mathrm{mg}$ /day in the morning on days 1-7, and a single 5-mg dose of axitinib administered with ketoconazole on day 4.

Axitinib and placebo treatment were administered in a single-blind manner, and ketoconazole treatment was not blinded. Subjects received axitinib or placebo in the morning after fasting overnight for at least $8 \mathrm{~h}$; food and beverages were permitted $4 \mathrm{~h}$ after dosing. The axitinib tablet formulation used in this study was previously shown to produce higher exposures in the overnight fasted state in a phase I study conducted in patients with solid tumors [7] and was the basis for administration of axitinib in the fasted state in the current study. Ketoconazole was administered with breakfast once daily in the morning, except on day 4 when it was administered simultaneously with axitinib after an overnight fast of at least $8 \mathrm{~h}$. During the first $4 \mathrm{~h}$ after dosing, subjects were required to refrain from lying down, except while BP, pulse rate, and ECG measurements were obtained.

\section{Assessments}

Blood samples $(5 \mathrm{ml})$ for determination of axitinib pharmacokinetic profiles were collected on days 1-3 at $0 \mathrm{~h}$ (pre-dose) and 1, 1.5, 2, 3, 4, 6, 8, 12, 16, 24, 36, and $48 \mathrm{~h}$ post-dose during treatment A. During treatment $\mathrm{B}$, samples were collected on days $4-8$ at $0 \mathrm{~h}$ (pre-dose) and at $1,1.5,2,3,4,6,8,12,16,24,36,48,72$, and
$96 \mathrm{~h}$ post-dose. Blood pressure and pulse rate were recorded in triplicate at screening, and single measurements were obtained on days -2 and -1 , days $1-3$ during treatment $\mathrm{A}$, on the day before commencing the second treatment, days 4-6 during treatment B, and at the end of the study. Standard 12-lead ECG tests were carried out at screening, days -2 and -1 , day 1 during treatment $A$, days 3 and 4 during treatment $B$, and at the end of the study. Assessments of ECG, BP, and pulse rate were performed prior to the collection of blood samples at the timepoints indicated above plus an additional assessment $10 \mathrm{~h}$ post-dose.

Safety and tolerability were assessed by monitoring adverse events, vital signs, ECGs, and laboratory evaluations, as well as through physical examinations. Adverse events were graded according to the National Cancer Institute Common Terminology Criteria for Adverse Events, version 3.0 (ctep.cancer.gov/protocoldevelopment/ electronic_applications/docs/ctcaev3.pdf).

\section{Bioanalytical methods}

Axitinib concentrations in potassium $\left(\mathrm{K}_{3}\right)$ EDTA plasma were measured using a validated liquid chromatography/ tandem mass spectrometric assay (Charles River Laboratories, Worcester, MA) with a range of 0.1 to $25 \mathrm{ng} / \mathrm{ml}$ [7]. Due to axitinib light sensitivity, all sample processing and bioanalytical procedures were performed under red light or with appropriate protection from visible light. Plasma samples were added to a 96-well opaque microtiter plate and fortified with deuterium-labeled (d7) axitinib internal standard, followed by addition of $1.0 \mathrm{M}$ sodium bicarbonate. The samples were extracted with ethyl acetate:hexanes $(75: 25, \mathrm{v} / \mathrm{v})$, centrifuged, and the supernatants were evaporated to dryness under a gentle nitrogen stream in microtiter plates heated to $35^{\circ} \mathrm{C}$. Sample residues were reconstituted in water/methanol/sodium bisulfite (75:25:0.5, $\mathrm{v} / \mathrm{v} / \mathrm{v}$ ) and eluted from a C18 column (XTerra ${ }^{\circledR}$ MS C18, $30 \times 2.1 \mathrm{~mm}, 3.5 \mu \mathrm{m}$; Waters Corporation, Milford, MA) using a multi-step gradient (mobile phase $\mathrm{A}=$ water, mobile

Fig. 2 Treatment overview

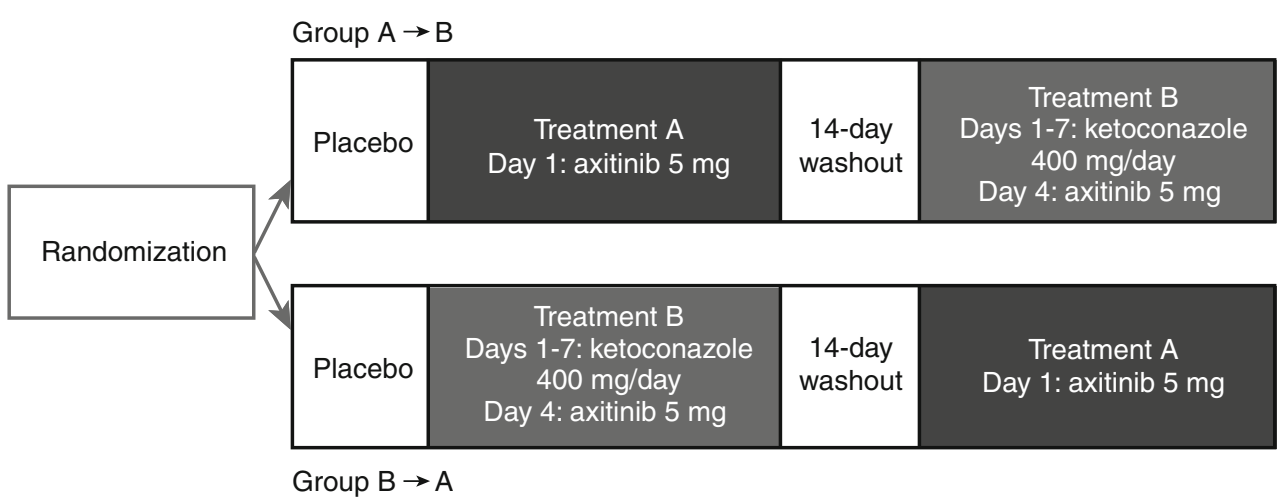


phase $\mathrm{B}=$ acetonitrile; $10-90 \% \mathrm{~B}$ in $3 \mathrm{~min} ; 0.5 \mathrm{ml} / \mathrm{min}$ flow rate) onto an API $3000^{\circledR}$ mass spectrometer (AB Sciex, Ontario, Canada) with an electrospray ionization source. Detection was in positive ion mode with multiple reaction monitoring (mass transition $[\mathrm{m} / \mathrm{z}] 387 \rightarrow 355$ and $394 \rightarrow 360$ for axitinib and axitinib-d7). Duplicate quality control (QC) samples at three concentration levels spanning the assay range (low, medium, and high) were included in each analytical run to measure assay performance. Interassay precision and accuracy were determined by QC samples from across all study sample runs. Precision was within $12 \%$ coefficient of variation (CV), while overall bias (expressed as percent relative error) was within $5.5 \%$. No plasma metabolites were characterized in the study.

Genotyping of drug-metabolizing enzymes was carried out using polymerase chain reaction (PCR) to amplify DNA samples for all assays performed in this study (Pfizer-Ann Arbor, Worldwide Safety Sciences, Ann Arbor, MI). In particular, the following variants of UGT1A1 were assessed: UGT1A1*60, UGT1A1-3156 (-3156 G $\rightarrow$ A nucleotide change), UGT1A1 Promoter TA repeat $(* 28$, *36, *37), UGT1A1*6 and UGT1A1*27. Genotyping for the CYP2C19*2,*3, and *17 alleles was also conducted. The TaqMan ${ }^{\circledR}$ Allelic Discrimination procedure was used for detection of all alleles, with the exception of the CYP3A4*2 (MassEXTENDTM; Sequenom, San Diego, $\mathrm{CA}$ ) and $U G T 1 A 1 * 28$ (sequencing) genotyping assays.

TaqMan ${ }^{\circledR}$ allelic discrimination assay

TaqMan ${ }^{\circledR}$ allelic discrimination employs the 5'-nuclease activity of AmpliTaq Gold ${ }^{\circledR}$ DNA polymerase to allow direct detection of PCR products by the release of a fluorescent reporter. Two TaqMan ${ }^{\circledR}$ probes (Applied Biosystems, Carlsbad, CA) were used in this assay, one probe for each allele. Each probe consists of an oligonucleotide with a $5^{\prime}$ reporter (TET TM [tetrachloro-6-carboxyfluorescein]/VIC ${ }^{\circledR}$ or FAM $^{\circledR}$ [6-carboxyfluoroscein] dye and a 3'quencher dye [TAMRA ${ }^{\mathrm{TM}}$ (6-carboxytetramethylrhodamine)] or a non-fluorescent quencher). An intact probe results in quenching of the reporter dye fluorescence.

During the annealing phase of PCR, forward and reverse primers hybridize to the flanking region of the polymorphic site. In addition, the TaqMan ${ }^{\circledR}$ probes hybridize to the target polymorphic site within the PCR product. The reporter dye is cleaved by the Taq Gold ${ }^{\circledR}$ enzyme, resulting in an increase in the reporter dye fluorescence. By measuring the intensities of TET $^{\mathrm{TM}} / \mathrm{VIC}^{\circledR}$ (allele 1 or homozygous wild type) and FAM ${ }^{\mathrm{TM}}$ (allele 2 or homozygous variant) signal, the specific genotype of an allele is discriminated.

Individual reaction plates with $20 \mathrm{ng}$ of genomic DNA per reaction were used. Master mixes were prepared for each assay performed, and controls for both no template and each allele were included for each plate. After master mix (10X PCR buffer with $\mathrm{MgCl}_{2}$, forward and reverse primers, TaqMan ${ }^{\circledR}$ probes, deoxynucleotides, and AmpliTaq Gold ${ }^{\circledR}$ DNA polymerase) had been added to the controls and unknown DNA samples, plates were sealed and PCR cycling (GeneAmp ${ }^{\circledR}$ PCR System 9700, Applied Biosystems) performed. The sealed 96-well plates were then transferred to the ABI $7700^{\circledR}$ (Applied Biosystems) and fluorescence data collected.

\section{Simcyp ${ }^{\circledR}$ simulations}

A Simcyp ${ }^{\circledR}$-based simulation (Simcyp ${ }^{\circledR}$ Population-based ADME Simulator, version 6.0 [Simcyp Ltd, Sheffield, UK] on Microsoft Windows ${ }^{\circledR}$ XP [Redmond, WA]) was performed to assess changes in axitinib plasma concentrations with co-administration of ketoconazole (inhibitor) in healthy volunteers. Simcyp ${ }^{\circledR}$ uses the relationship between the inhibitor concentration at the active site in vivo and the inhibition constant $\left(\mathrm{K}_{\mathrm{i}}\right)$ determined in vitro to predict the effects of drug-drug interactions involving CYP enzymes. Competitive inhibition, induction, and/or mechanism-based inhibition can be investigated using this software [11].

A Simcyp ${ }^{\circledR}$ model was developed for axitinib using in vitro and clinical pharmacokinetic parameters for axitinib (input parameters are shown in Table 1). The required Simcyp ${ }^{\circledR}$ model for ketoconazole was available within Simcyp ${ }^{\circledR}$ as an inhibitor file. Due to the inability to determine glucuronidation clearance from in vitro tissues accurately, the following approach was used. Systemic clearance $\left(\mathrm{CL}_{\mathrm{sys}}\right)$ for axitinib was determined from a previous study in healthy volunteers who received intravenous axitinib $(1 \mathrm{mg})$. In vivo $\mathrm{CL}_{\text {sys }}$ was then converted to intrinsic clearance $\left(\mathrm{CL}_{\text {int }}\right)$ using amount of microsomal protein per gram of liver and liver weight to yield a $\mathrm{CL}_{\text {int }}$ of $500 \mu \mathrm{l} / \mathrm{min} / \mathrm{mg}$ microsomal protein. Contribution of CYP3A and glucuronidation to total $\mathrm{CL}_{\text {int }}$ was determined through sensitivity analyses to be $50 \%$ (CYP3A4 $=250 \mu \mathrm{l} /$ $\mathrm{min} / \mathrm{mg}$ microsomal protein) and 30\% (non-CYP-mediated clearance $=150 \mu \mathrm{l} / \mathrm{min} / \mathrm{mg}$ ), respectively, when simulations with ketoconazole were conducted. The remaining $20 \%$ of clearance was attributed to non-metabolic pathways $(4.2 \mathrm{~L} / \mathrm{h})$.

Physiologic variability (healthy Northern European Caucasians: height, weight, age, etc.) and variation in phenotype were calculated using parameters within the Simcyp ${ }^{\circledR}$ software. Dose, dose interval, and duration of administration of axitinib and ketoconazole were set according to the clinical protocol. Simcyp ${ }^{\circledR}$ predicts the mean value as well as the distribution in the population for the effect by applying a Monte Carlo approach. Population simulations were performed using 100 Northern European Caucasians aged 20-50 years (1:1 male/ female) in 10 trials, with each trial containing 10 subjects. To prevent bias, the Simcyp ${ }^{\circledR}$ end-user did not have access to the clinical drug-drug interaction results. 
Table 1 In vitro input parameters used in Simcyp ${ }^{\circledR}$ model

\begin{tabular}{|c|c|c|}
\hline Input parameter & Value & Data source \\
\hline Molecular weight & 386.47 & \\
\hline $\log \mathrm{P}$ & 3.1 & In vitro determination \\
\hline $\mathrm{B} / \mathrm{P}$ ratio & 0.79 & In vitro determination \\
\hline fu plasma & 0.02 & In vitro plasma protein binding \\
\hline fa & 1 & Assumption \\
\hline $\mathrm{ka}(1 / \mathrm{h})$ & 0.7 & Estimated as $\sim 1 / T_{\max } ; T_{\max }$ from clinical data \\
\hline Vss (L/kg) & 1 & Clinical data \\
\hline fu microsomal & 1 & Simcyp ${ }^{\circledR}$ in silico calculator \\
\hline Q gut $(\mathrm{L} / \mathrm{h})$ & 10 & Based upon Caco-2 cell permeability data \\
\hline $\mathrm{CL}_{\text {int }}(\mathrm{ul} / \mathrm{min} / \mathrm{mg}-$ microsomal protein $)$ & 250 & Experimental; for $\mathrm{P}_{450}$ contribution \\
\hline Additional undefined HLM $\mathrm{CL}_{\text {int }}$ & 150 & Experimental; for non- $\mathrm{P}_{450}$ (glucuronidation) contribution \\
\hline
\end{tabular}

$P$ partition coefficient, $B / P$ ratio blood to plasma ratio for axitinib, fu plasma fraction of drug unbound in plasma, fa fraction absorbed from gastrointestinal tract, $k a$ first-order rate of absorption, Vss volume of distribution at steady state, fu microsomal fraction of drug unbound in microsomal fraction, $Q_{g u t}$ intestinal blood flow, $C L_{i n t}$ intrinsic clearance, $H L M$ human liver microsomes

Statistical and pharmacokinetic analyses

Based on an $\mathrm{IC}_{50}$ of $0.4 \mu \mathrm{M}$ for ketoconazole-mediated inhibition of axitinib metabolism observed in human liver microsomal preparations, ketoconazole $400 \mathrm{mg}$ was predicted to result in a 1.8 -fold increase in axitinib geometric mean AUC from time zero to infinity $\left(\mathrm{AUC}_{0-\infty}\right)$ and a 1.5 fold increase in geometric mean $\mathrm{C}_{\max }$.

The standard deviation (SD) of the difference between (natural $\log$ ) $\mathrm{AUC}_{0-\infty}$ of axitinib plus ketoconazole and axitinib alone was estimated to be 0.42 , based on variability in axitinib pharmacokinetics observed in the FIH phase I study in patients with solid tumors [7]. The sample size was calculated as 24 subjects (12 per sequence) to provide $80 \%$ power to ensure that the lower limit of the $90 \%$ confidence interval (CI) for the AUC ratio was above 1.6 (a $60 \%$ increase), if ketoconazole treatment increased axitinib exposure by $100 \%$.

Data analyses included all subjects who received at least one dose of study medication (placebo, axitinib, or ketoconazole). In addition, evaluable pharmacokinetic data were required for analyses of pharmacokinetic parameters, and at least one baseline and post-baseline BP measurement were needed for BP analyses.

Pharmacokinetic evaluation of axitinib was performed with WinNonlin ${ }^{\circledR}$, version 4.01 (Pharsight, Mountain View, CA) using a non-compartmental approach. Estimated axitinib pharmacokinetic parameters included AUC, $\mathrm{C}_{\max }$, and half-life $\left(t_{1 / 2}\right)$. The primary analysis for the study was based on axitinib $\mathrm{AUC}_{0-\infty}$. This value was log-transformed and analyzed using a mixed-effects model with treatment, period, and sequence as fixed effects and subject (nested within sequence) as the random effect. The $90 \%$ CI for the difference in the means of the log-transformed $\mathrm{AUC}_{0-\infty}$ was calculated. The antilogs of the confidence limits obtained constituted the $90 \%$ CI for the ratio of the geometric mean of ketoconazole plus axitinib compared with axitinib alone. Secondary analyses were performed using axitinib AUC from time zero to the time of last quantifiable concentration $\left(\mathrm{AUC}_{\text {last }}\right)$ and $\mathrm{C}_{\max }$ in a similar fashion.

\section{Results}

Subject characteristics and disposition

A total of 35 subjects were enrolled, 20 of whom were randomized to group $\mathrm{A} \rightarrow \mathrm{B}$ and 15 of whom were randomized to group $\mathrm{B} \rightarrow \mathrm{A}$. Baseline characteristics were comparable between subjects in the two groups (Table 2). The majority of participants were male (91.4\%) and the median age was 32 years (range: 19-54 years). Thirty-two subjects received at least one dose of axitinib; 28 subjects ( $80 \%$ of the 35 enrolled subjects) completed the study. The remaining seven subjects discontinued at the investigator's discretion, i.e., serum chemistry abnormalities before receiving axitinib $(n=2)$; positive cotinine test after the washout period $(n=1)$; difficulty swallowing $(n=1)$, withdrawal of consent $(n=2)$, or terminated due to an adverse event assessed as unrelated to treatment ( $n=1$, grade 1 increased serum creatinine).

Pharmacokinetics

In all, 32 subjects were included in the pharmacokinetic analysis, which included data for 31 subjects treated with axitinib alone and 28 subjects treated with axitinib plus ketoconazole. 
Table 2 Subject characteristics at baseline

\begin{tabular}{|c|c|c|c|}
\hline & Group $\mathrm{A} \rightarrow \mathrm{B}(n=20)$ & Group $\mathrm{B} \rightarrow \mathrm{A}(n=15)$ & Total $(N=35)$ \\
\hline \multicolumn{4}{|l|}{ Sex, n (\%) } \\
\hline Male & $18(90.0)$ & $14(93.3)$ & $32(91.4)$ \\
\hline Female & $2(10.0)$ & $1(6.7)$ & $3(8.6)$ \\
\hline Age, median (min, max), years & $33.5(19,54)$ & $32.0(21,53)$ & $32.0(19,54)$ \\
\hline \multicolumn{4}{|l|}{ Race, n (\%) } \\
\hline Black & $2(10.0)$ & $2(13.3)$ & $4(11.4)$ \\
\hline Caucasian & $10(50.0)$ & $9(60.0)$ & $19(54.3)$ \\
\hline Hispanic/Latino & $7(35.0)$ & $3(20.0)$ & $10(28.6)$ \\
\hline Other & $1(5.0)$ & $1(6.7)$ & $2(5.7)$ \\
\hline Systolic BP at baseline, median (min, max), $\mathrm{mm} \mathrm{Hg}$ & $114.0(96,135)$ & $112.0(98,135)$ & $114.0(96,135)$ \\
\hline Diastolic BP at baseline, median (min, $\max$ ), $\mathrm{mm} \mathrm{Hg}$ & $67.5(58,86)$ & $72.0(62,83)$ & $70.0(58,86)$ \\
\hline
\end{tabular}

$B P$ blood pressure

All pre-dose axitinib concentrations were below the lower limit of quantification $(0.100 \mathrm{ng} / \mathrm{ml})$, demonstrating that the washout period between treatments $\mathrm{A}$ and $\mathrm{B}$ was sufficient. QC assay performance had an average accuracy within $6 \%$ and average precision was within $13 \% \mathrm{CV}$. As expected, median plasma concentrations of axitinib were higher following combination treatment with ketoconazole and axitinib compared with axitinib treatment alone (Fig. 3). Similarly, axitinib exposure was significantly increased in the presence of ketoconazole, with a geometric mean ratio for $\mathrm{AUC}_{0-\infty}$ of 2.06 (90\% CI: 1.84-2.30) and a geometric mean ratio for $\mathrm{C}_{\max }$ of 1.50 (90\% CI: 1.33-1.70) (Table 3). The mean plasma $t_{1 / 2}$ of axitinib increased following co-administration with ketoconazole to $13.1 \mathrm{~h}$ (SD: 8.85), compared with $9.44 \mathrm{~h}$ (SD: 9.98) following axitinib treatment alone. Ketoconazole treatment did not appear to have any effect on axitinib median time to reach $\mathrm{C}_{\max }\left(\mathrm{T}_{\max }\right.$ ). Values for $\mathrm{T}_{\max }$ were $1.50 \mathrm{~h}$ (range: 1.00 3.00) for axitinib alone and $2.00 \mathrm{~h}$ (range: 1.00-4.13) for axitinib plus ketoconazole.

Genotypic analysis of axitinib drug-metabolizing enzymes

Since axitinib metabolism has minor contributions from two genetically polymorphic enzymes, CYP2C19 and UGT1A1, genotyping for these enzymes was included here and in most axitinib studies conducted in healthy volunteers. The intent of the genotyping is to conduct a pooled meta-analysis of the influence of polymorphic enzymes on inter-subject variability in axitinib drug exposure. Due to a
Fig. 3 Median axitinib concentration-time profiles following treatment with axitinib alone $(n=31)$ or axitinib plus ketoconazole $(n=29)$, linear scale a and $\log$ scale $\mathbf{b}$
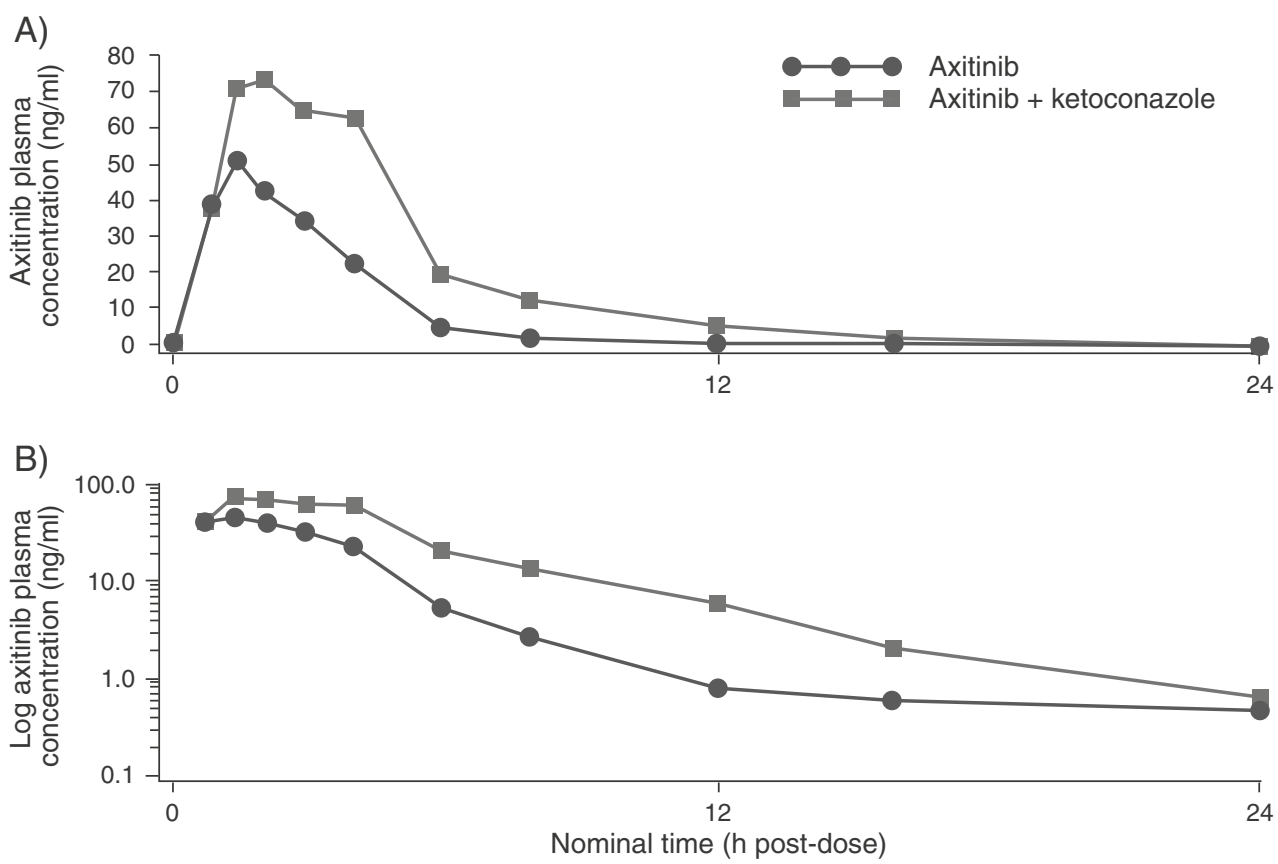
Table 3 Summary of axitinib PK parameters (evaluable population; $n=32$ )

\begin{tabular}{|c|c|c|c|c|}
\hline & \multicolumn{2}{|c|}{ Geometric LS mean $(95 \% \mathrm{CI})$} & \multicolumn{2}{|l|}{ Statistical comparison } \\
\hline & Axitinib $(n=31)$ & Axitinib + ketoconazole $(n=28)$ & Geometric LS mean ratio & $90 \% \mathrm{CI}$ \\
\hline $\operatorname{AUC}_{0-\infty}(\mathrm{ng} \cdot \mathrm{h} / \mathrm{ml})$ & $196.7(162.0-238.8)$ & $404.8(332.3-493.2)$ & 2.06 & $1.84-2.30$ \\
\hline $\mathrm{AUC}_{\text {last }}(\mathrm{ng} \cdot \mathrm{h} / \mathrm{ml})$ & $193.8(159.9-234.9)$ & $401.9(330.1-489.3)$ & 2.07 & $1.86-2.31$ \\
\hline $\mathrm{C}_{\max }(\mathrm{ng} / \mathrm{ml})$ & $51.0(43.9-59.3)$ & $76.7(65.6-89.7)$ & 1.50 & $1.33-1.70$ \\
\hline
\end{tabular}

$A U C_{0-\infty}$ area under the plasma concentration-time curve from time zero to infinity, $A U C_{\text {last }}$ area under the plasma concentration-time curve from time zero to the time of last quantifiable concentration, $C I$ confidence interval, $C_{\max }$, maximum plasma concentration, $L S$, least squares

lack of statistical power, it was not possible to assess the effect of genotype on axitinib pharmacokinetics from this study alone.

\section{Simcyp ${ }^{\circledR}$ simulation}

The Simcyp ${ }^{\circledR}$ simulation was conducted using a design that mirrored the clinical ketoconazole drug interaction study design. The Simcyp ${ }^{\circledR}$ simulations predicted a 2.08-fold increase in $\mathrm{AUC}$ and a 1.41-fold increase in $\mathrm{C}_{\max }$ for axitinib in the presence of ketoconazole. The overall predicted shift in axitinib plasma concentration by Simcyp ${ }^{\circledR}$ was similar to that observed clinically in the presence of ketoconazole (2.06-fold increase in $\mathrm{AUC}_{0-\infty} ; 1.50$-fold increase in $\mathrm{C}_{\max }$ ).

\section{Pharmacodynamics}

Mean time-matched changes from baseline in BP were minimal and followed similar trends for axitinib treatment alone and in combination with ketoconazole (Fig. 4). Mean values for systolic and diastolic BP were within normal ranges. Findings from the QTc analysis will be reported elsewhere.

Safety and tolerability

Adverse events were generally mild and resolved without treatment, as expected in this population of healthy volunteers. One subject $(2.9 \%$ of all subjects) in group $\mathrm{A} \rightarrow \mathrm{B}$ experienced grade 2 nausea and vomiting during treatment with axitinib plus ketoconazole. No action was required, and the adverse event resolved before the end of the study. All other treatment-emergent adverse events, regardless of causality, were grade 1 . No grade 3 or 4 laboratory abnormalities were reported. Treatment-related adverse events were reported in eight volunteers $(40.0 \%)$ in group $\mathrm{A} \rightarrow \mathrm{B}$ and in one volunteer $(6.7 \%)$ in group $\mathrm{B} \rightarrow \mathrm{A}$. Treatment-related adverse events primarily affected the nervous system (e.g., dizziness or headache) or gastrointestinal system (e.g., nausea) (Table 4). Most treatmentrelated adverse events occurred during treatment with ketoconazole alone or with axitinib plus ketoconazole.
Fig. 4 Mean change from baseline in a systolic and $\mathbf{b}$ diastolic blood pressure $(B P)$
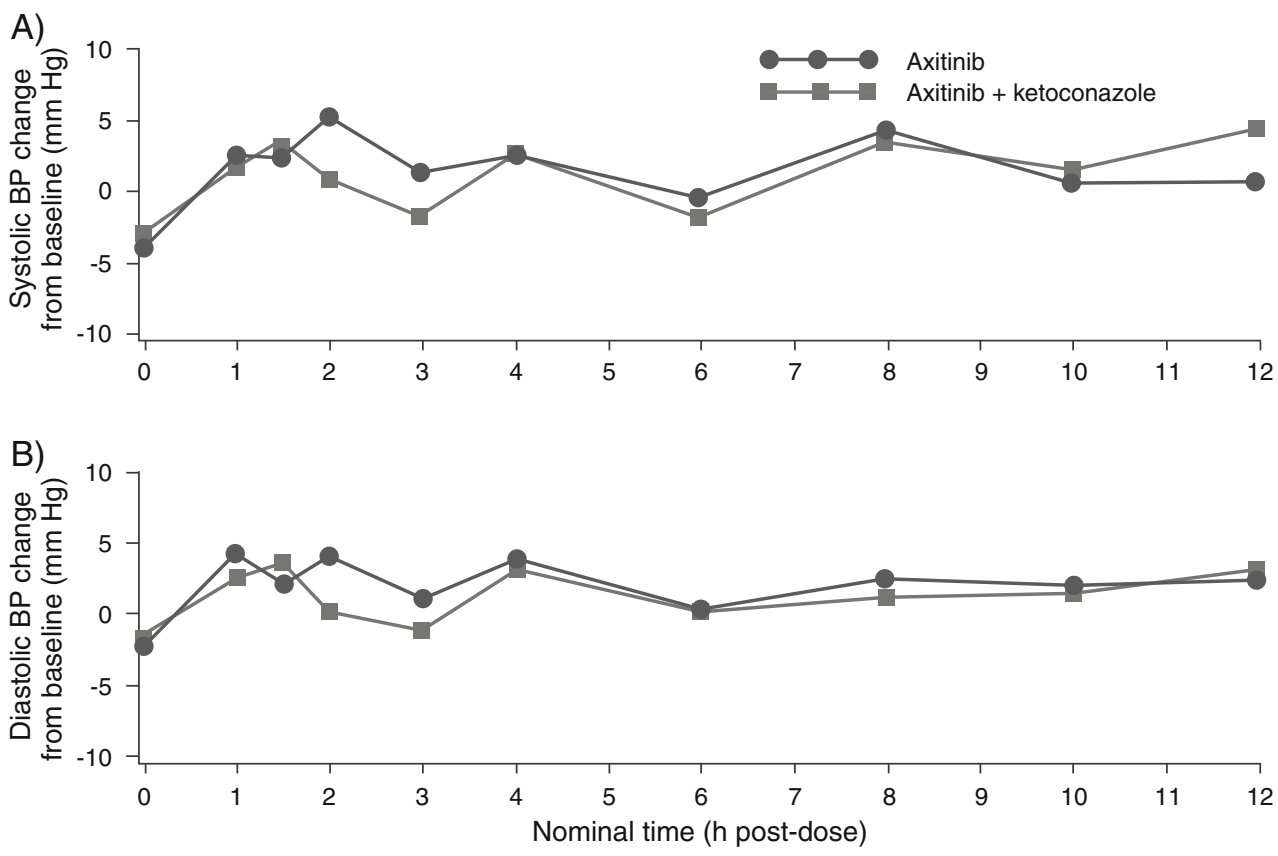
Table 4 Treatment-related adverse events (AEs) for prescribed treatment at time of $\mathrm{AE}^{\mathrm{a}}$

NOS not otherwise specified

${ }^{\mathrm{a}}$ No treatment-related AEs were reported during prescribed treatment with placebo

${ }^{\mathrm{b}}$ No AEs grade $\geq 2$ were reported

\begin{tabular}{lllll}
\hline AE, $n(\%)$ & Axitinib $(n=32)$ & \multicolumn{2}{l}{ Ketoconazole $(n=29)$} & \multicolumn{2}{l}{ Axitinib+ketoconazole $(n=28)$} \\
\cline { 4 - 5 } & Grade $1^{\mathrm{b}}$ & Grade $1^{\mathrm{b}}$ & Grade 1 & Grade 2 \\
\hline Any AE & $2(6.3)$ & $3(10.3)$ & $5(17.9)$ & $1(3.6)$ \\
Headache NOS & $1(3.1)$ & $3(10.3)$ & $3(10.7)$ & 0 \\
Nausea & 0 & $2(6.9)$ & $2(7.1)$ & $1(3.6)$ \\
Dizziness & 0 & $2(6.9)$ & $1(3.6)$ & 0 \\
Loose stools & $1(3.1)$ & 0 & $1(3.6)$ & 0 \\
Dysgeusia & $1(3.1)$ & 0 & 0 & 0 \\
Blurred vision & 0 & $1(3.4)$ & 0 & 0 \\
Gastritis NOS & 0 & $1(3.4)$ & 0 & 0 \\
Vomiting NOS & 0 & 0 & 0 & $1(3.6)$ \\
\hline
\end{tabular}

\section{Discussion}

Data from this study represent maximized axitinib exposures obtained when axitinib is co-administered with ketoconazole, a drug that inhibits CYP3A activity. Concomitant treatment with ketoconazole significantly increased axitinib exposure, resulting in a $\sim 2$-fold increase in geometric mean axitinib $\mathrm{AUC}_{0-\infty}$ and a $\sim 1.5$-fold increase in geometric mean $\mathrm{C}_{\max }$. These findings support the exclusion criteria in ongoing axitinib studies for patients to avoid concurrent treatment with potent inhibitors of CYP3A. These data are also useful in quantitatively predicting the magnitude of change in axitinib exposure (i.e., no more than 2-fold) expected when potent CYP3A inhibitors other than ketoconazole are administered together with axitinib.

Based on data from human liver microsomal preparations (unpublished data), ketoconazole was predicted to result in a 1.8-fold increase in axitinib geometric mean $\mathrm{AUC}_{0-\infty}$. Similarly, the Simcyp ${ }^{\circledR}$ prediction was a 2.08 -fold increase in axitinib plasma concentrations in the presence of ketoconazole. The clinical result (2.06-fold increase) was similar to these pre-clinical predictions and confirms the validity of this simulation.

Although this study was not sufficiently powered to evaluate the effect of genotypic variation in drugmetabolizing enzymes on axitinib pharmacokinetics, data from this trial were included in a separate population pharmacokinetic analysis that evaluated the potential effect of the UGTA1A1*28 genotype on axitinib pharmacokinetics in 119 healthy volunteers [12]. In the population pharmacokinetics model, the UGT1A1*28 genotype was not identified as a significant covariate for oral clearance (CL/ F). However, the model predicted that subjects who are homozygous or heterozygous for this mutation are predisposed to have reductions in $\mathrm{CL} / \mathrm{F}$ of $10 \%$ and $5 \%$, respectively, compared with individuals homozygous for the wild-type gene. At the highest simulated dose $(10 \mathrm{mg}$
BID), the upper $90 \%$ bound for the predicted AUC distribution in homozygous variant subjects was lower than the plasma exposure associated with unacceptable toxicity in the FIH phase I dose-escalation study in patients [7]. Based on these findings, axitinib dose modification in patients based on $U G T 1 A 1 * 28$ genotype is not warranted at this time.

Administration of a single dose of axitinib in combination with repeated ketoconazole treatment was well tolerated. Most treatment-related adverse events affected the nervous or gastrointestinal systems, with headache and nausea reported most frequently during combination treatment $(n=10.7 \%$ each). With the exception of one patient who experienced grade 2 nausea and vomiting, all other treatment-related adverse events were mild in severity (grade 1). No clinically significant effects on diastolic or systolic BP were observed for axitinib plus ketoconazole treatment compared with axitinib treatment alone. Treatment-related adverse events reported for axitinib treatment alone were similar to those reported in other clinical trials with axitinib [2-6].

In conclusion, axitinib treatment was well tolerated in this study, both alone and in combination with ketoconazole. However, as predicted, axitinib and ketoconazole co-administration significantly increased axitinib plasma exposure and peak concentrations in healthy volunteers compared with axitinib alone. Concomitant treatment with potent CYP3A4 inhibitors and axitinib should be avoided since the combination may increase the frequency or severity of adverse events.

Acknowledgments Medical writing support was provided by Molly Heitz at $\mathrm{ACUMED}^{\circledR}$ (Tytherington, UK) and Joanna Bloom, PhD, at UBC Scientific Solutions (Southport, CT, USA), which was funded by Pfizer Inc. The study was sponsored by Pfizer Inc.

Disclosure statement YKP, KJK, JM, MG, BH, PS, and SVR are employees of Pfizer and own stock in Pfizer. NS was an employee of Pfizer, the sponsor of the study, during the study. WT was employed as a student assistant at Pfizer while helping to prepare the manuscript. 
Open Access This article is distributed under the terms of the Creative Commons Attribution Noncommercial License which permits any noncommercial use, distribution, and reproduction in any medium, provided the original author(s) and source are credited.

\section{References}

1. Hu-Lowe DD, Zou HY, Grazzini ML, Hallin ME, Wickman GR, Amundson K, Chen JH, Rewolinski DA, Yamazaki S, Wu EY, McTigue MA, Murray BW, Kania RS, O'Connor P, Shalinsky DR, Bender SL (2008) Nonclinical antiangiogenesis and antitumor activities of axitinib (AG-013736), an oral, potent, and selective inhibitor of vascular endothelial growth factor receptor tyrosine kinases 1, 2, 3. Clin Cancer Res 14:7272-7283. doi:10.1158/ 1078-0432.CCR-08-0652

2. Rixe O, Bukowski RM, Michaelson MD, Wilding G, Hudes GR, Bolte O, Motzer RJ, Bycott P, Liau KF, Freddo J, Trask PC, Kim S, Rini BI (2007) Axitinib treatment in patients with cytokinerefractory metastatic renal-cell cancer: a phase II study. Lancet Oncol 8:975-984. doi:10.1016/S1470-2045(07)70285-1

3. Fruehauf J, Lutzky J, McDermott D, Brown CK, Pithavala Y, Bycott P, Shalinsky D, Liau KF, Niethammer A, Rixe O (2008) Axitinib (AG-013736) in patients with metastatic melanoma: a phase II study. J Clin Oncol (Meeting Abstracts) 26: 9006.

4. Rini BI, Wilding G, Hudes G, Stadler WM, Kim S, Tarazi J, Rosbrook B, Trask PC, Wood L, Dutcher JP (2009) Phase II study of axitinib in sorafenib-refractory metastatic renal cell carcinoma. J Clin Oncol 27:4462-4468. doi:10.1200/JCO.2008.21.7034

5. Schiller JH, Larson T, Ou SH, Limentani S, Sandler A, Vokes E, Kim S, Liau K, Bycott P, Olszanski AJ, von Pawel J (2009) Efficacy and safety of axitinib in patients with advanced nonsmall-cell lung cancer: results from a phase II study. J Clin Oncol 27:3836-3841. doi:10.1200/JCO.2008.20.8355
6. Cohen EE, Rosen LS, Vokes EE, Kies MS, Forastiere AA, Worden FP, Kane MA, Sherman E, Kim S, Bycott P, Tortorici M, Shalinsky DR, Liau KF, Cohen RB (2008) Axitinib is an active treatment for all histologic subtypes of advanced thyroid cancer: results from a phase II study. J Clin Oncol 26:4708-4713. doi:10.1200/JCO.2007.15.9566

7. Rugo HS, Herbst RS, Liu G, Park JW, Kies MS, Steinfeldt HM, Pithavala YK, Reich SD, Freddo JL, Wilding G (2005) Phase I trial of the oral antiangiogenesis agent AG-013736 in patients with advanced solid tumors: pharmacokinetic and clinical results. J Clin Oncol 23:5474-5483

8. Pithavala YK, Tortorici M, Toh M, Garrett M, Hee B, Kuruganti U, Ni G, Klamerus KJ (2010) Effect of rifampin on the pharmacokinetics of Axitinib (AG-013736) in Japanese and Caucasian healthy volunteers. Cancer Chemother Pharmacol 65: 563-570. doi:10.1007/s00280-009-1065-y

9. Zientek M, Kang P, Jiang Y, Neul D, Friewald S, Smith BJ (2010) In vitro kinetic characterization of axitinib metabolism to estimate the clinical implications of genetic polymorphisms. International Society for the Study of Xenobiotics-Workshop on Genetic Polymorphisms in Drug Disposition; Indianapolis, IN, April 1113,2010

10. Takeda S, Kitajima Y, Ishii Y, Nishimura Y, Mackenzie PI, Oguri K, Yamada H (2006) Inhibition of UDP-glucuronosyltransferase 2b7-catalyzed morphine glucuronidation by ketoconazole: dual mechanisms involving a novel noncompetitive mode. Drug Metab Dispos 34:1277-1282

11. Rakhit A, Pantze MP, Fettner S, Jones HM, Charoin JE, Riek M, Lum BL, Hamilton M (2008) The effects of CYP3A4 inhibition on erlotinib pharmacokinetics: computer-based simulation (SimCYP) predicts in vivo metabolic inhibition. Eur J Clin Pharmacol 64:31-41. doi:10.1007/s00228-007-0396-Z

12. Garrett M, Houk BE, Myrand SP, Hee B, Mota J, Pithavala YK (2007) A population pharmacokinetic (PK) analysis to evaluate the potential effect of the UGT1A1*28 genotype on the PK of AG013736, an anti-angiogenic agent. Clin Pharmacol Ther 81:S21-S21 